\title{
Bioactivities of Bruguiera gymnorrhiza and profiling of its bioactive polyphenols by HPLC-DAD
}

\author{
Imtiaz Mahmud, Md. Nazmul Hasan Zilani, Nripendra Nath Biswas and Bishwajit Bokshi*
}

\begin{abstract}
Background: In folk medicine leaves and stem of Bruguiera gymnorrhiza (L.) are commonly used to treat diarrhea, fever, diabetes, pain and a number of ailments. The present study was carried out to explore antioxidant, analgesic and antidiarrhoeal activities of ethanol extract of leaves and stem of B. gymnorrhiza and also to analyze its major bioactive natural polyphenols by HPLC-DAD.

Methods: Total polyphenol content was spectrophotometrically determined using Folin Chiocalteu's reagent while the flavonoids by aluminum chloride colorimetric assay. Antioxidant activity was determined by DPPH free radical scavenging, reducing power, nitric oxide and hydrogen peroxide scavenging assays. Identification and quantification of bioactive polyphenols were done by HPLC-DAD method. Antidiarrhoeal activity of the extracts was evaluated using experimentally castor oil induced diarrhea in mice. Acetic acid induced writhing method was used to evaluate the analgesic activity. Acute oral toxicity and brine shrimp lethality assay were performed to check the cytotoxic potential.
\end{abstract}

Results: Both the leave and stem extracts contain significant amount of phenolic and flvonoid content. Extracts showed DPPH radical scavenging, nitric oxide, hydrogen peroxide scavenging and also concentration dependent reducing power activity. HPLC analysis of both extract indicated the presence of significant amount of vanillic acid along with other phenolic constituents. Both extracts showed significant $(P<0.01)$ analgesic and antidiarrhoeal activity. Furthermore, extracts showed negligible toxic effect.

Conclusion: Along with other phenolic compounds, vanillic acid present in the extract may be responsible for antioxidant, analgesic and antidiarrhoeal activities. Altogether these results rationalize the use of this plant in traditional medicine.

Keywords: Polyphenol, HPLC, Vanillic acid, Analgesic activity, Antidiarrhoeal activity

\section{Background}

Natural products are supposed to be an important source of new chemical substances with potential therapeutic applications. The medicinal value of the plants lies in some chemical active substances that produce a definite pharmacological action on biological system. The most important of these chemically active constituents of plants are alkaloid, tannin, flavonoid and phenolic compounds $[1,2]$. Since antiquity many plants are used as folk medicine to treat infectious diseases such as urinary tract infections, diarrhoea,

\footnotetext{
* Correspondence: bokshi06@yahoo.com

Pharmacy Discipline, Life Science School, Khulna University, Khulna 9208, Bangladesh
}

cutaneous abscesses, bronchitis and parasitic diseases [3]. In the last few years, a number of studies have been conducted in different medicinal plants in different countries to prove the medicinal efficiency $[4,5]$. Bangladesh owing to its favorable climatic influences has been blessed with massive natural resources including explored and unexplored medicinal plants [6, 7]. Several plant species of Bangladesh are traditionally used to treat different ailments. Some of them are also used to treat pain and diarrhea.

Bruguiera gymnorrhiza (L.) (Rhizophoraceae) is an evergreen mangrove tree, widely distributed in tropical and subtropical coastlines. In Bangladesh it is mainly found in the Sundarbans. In folk medicine fruits, barks 
and leaves are commonly used to treat diarrhea, fever, diabetes, pain, burns, intestinal worms, and liver disorders [8]. Previous investigations on this plant have shown the presence of Brugunin A; Bruguierol D; Bruguierols A, B, C; Aminopyrine; 7,3',4', 5'-tetrahydroxy-5-methoxyflavone; 3- $\beta$-(Z)-coumaroyllupeol; Menisdaurillide; Vomifoliol; Bruguiesulfurol; Apiculol; Steviol [9-11].

To the best of our knowledge, very few pharmacological studies have been reported so far on B. gymnorrhiza, the medicinal plant of the Sundarbans. As a part of the continuation of our research on bioactivity screening of Bangladeshi medicinal plants, present study was carried out to assess antioxidant, analgesic, antidiarrhoeal, activities and HPLC profiling of leaves and stem extracts of $B$. gymnorrhiza in order to scientifically evaluate the claimed biological activities.

\section{Methods}

\section{Chemicals and reagents}

2, 2-Diphenyl-1-picryldydrazyl (DPPH), ascorbic acid, arbutin (AR), gallic acid (GA), hydroquinone (HR), $(+)$-catechin $(\mathrm{CH})$, vanillic acid (VA), caffeic acid (CA), syringic acid (SA), (-)-epicatechin (EC), vanillin (VL), p-coumaric acid (PCA), trans-ferulic acid (TFA), rutin hydrate (RH), ellagic acid (EA), benzoic acid (BA), rosmarinic acid (RA), myricetin (MC), quercetin (QU), trans-cinnamic acid (TCA), kaempferol (KF) and butylated hydroxy toluene (BHT) were purchased from Sigma-Aldrich (St. Louis, MO, USA). Ethanol and HPLC grade acetonitrile, methanol, acetic acid were obtained from Merck (Darmstadt, Germany). Standard drug diclofenac sodium, loperamide hydrochloride and vincristine sulfate were purchased from Square Pharmaceuticals Ltd. and Beacon Pharmaceuticals Ltd. Bangladesh respectively.

\section{Plant materials and extraction}

For the present investigation the leaf and stem of Bruguiera gymnorrhiza were collected from the Sundarban of Khulna, Bangladesh area in April 2015 and were identified by expert at the Bangladesh National Herbarium (Accession no.: DACB-41874), Dhaka, Bangladesh. The shade dried plant parts were ground into a coarse powder with the help of a suitable grinder (Capacitor start motor, Wuhu motor factory, China). About $150 \mathrm{gm}$ powder of stem and $250 \mathrm{gm}$ of leaf were macerated in $800 \mathrm{ml}$ and $1000 \mathrm{ml}$ of $95 \%$ ethanol of about twelve days. After filtration and evaporation of solvent the yield of the stem and leaf extract was 2.8 and $6.7 \% \mathrm{w} / \mathrm{w}$ respectively and it was stored at $4{ }^{\circ} \mathrm{C}$ until analysis commenced.

\section{Experimental animals}

Young Swiss-albino mice aged 4-5 weeks, average weight $18-25 \mathrm{~g}$ were used for the experiment. The mice were purchased from the Animal Research Branch of the International Centre for Diarrhoeal Disease and Research, Bangladesh (ICDDR, B). They were kept in standard environmental condition (Temperature of $24 \pm$ $1{ }^{\circ} \mathrm{C} ; 12 \mathrm{~h}$ light and dark cycle with controlled humidity) for one week for adaptation after purchase and fed standard pellet diet and water ad libitum properly.

\section{Phytochemical screening}

Qualitative phytochemical tests were carried out for the identification of alkaloids, glycosides, flavonoids, saponins, tannin, gums, and terpenoids in the samples [12]. Alkaloids were detected using the Dragendroff's, Mayer's, Hager's and Wagner's tests. Lead acetate, alkaline reagent, ferric chloride and ammonia tests were used for detection of flavonoids. Legal's test, Molisch, Keller-Kiliani and Borntrager's tests were performed to identify glycosides. For identification of tannin potassium dichromate test, ferric chloride, potassium hydroxide and lead acetate tests were followed. Salkowski test and froth test were used to detect the presence of terpenoids and for saponins respectively. Molisch test was performed for detecting the existence of gum in the samples.

\section{Total phenolic content}

The total phenolic content of the extracts of B. gymnorrhiza was determined by the modified Folin-Ciocalteu method [13]. In $0.5 \mathrm{ml}$ extract $(1 \mathrm{mg} / \mathrm{ml}), 5 \mathrm{ml}$ of $10 \%$ $(\mathrm{v} / \mathrm{v})$ Folin-Ciocalteu reagent and $4 \mathrm{ml}$ of sodium carbonate $(75 \mathrm{~g} / \mathrm{L})$ solution were added. The mixture was vortexed for $15 \mathrm{~s}$ and allowed to incubate at $40{ }^{\circ} \mathrm{C}$ for $30 \mathrm{~min}$. The absorbance of the resultant mixture was measured at $765 \mathrm{~nm}$ against the suitable blank by using Shimadzu UV-visible spectrophotometer (Model 1800, Japan). The standard curve was prepared using different concentration ( 0.1 to $0.5 \mathrm{mg} / \mathrm{mL}$ ) of gallic acid.. Based on the measured absorbance of the extracts, total phenolic content of both extracts was calculated and expressed in terms of milligram of gallic acid equivalent (GAE) per gram of dry extract.

\section{Total flavonoid content}

The total flavonoid content of the extracts was determined according to aluminum chloride colorimetric method [14]. In $1 \mathrm{ml}$ extract solution $(1 \mathrm{mg} / \mathrm{ml}), 4 \mathrm{ml}$ distilled water and $0.3 \mathrm{ml}$ sodium nitrate $(50 \mathrm{~g} / \mathrm{L})$ were successively mixed. Five minutes later, $0.3 \mathrm{ml}$ aluminum chloride $(100 \mathrm{~g} / \mathrm{L})$ was added to the mixture with constant shaking. At the sixth minute $2 \mathrm{ml}$ of $1 \mathrm{M}$ sodium hydroxide was added and the volume was adjusted to $10 \mathrm{ml}$. Then absorbance was measured at $510 \mathrm{~nm}$. For this assay quercetin was used as standard. Based on the measured absorbance of the extracts, Quercetin 
Equivalent $(\mathrm{QE})$ was calculated from the calibration line and then total flavonoid content (TFC) in plant extract was expressed in terms of milligram of quercetin equivalent $(\mathrm{QE})$ per gram of dry extract.

\section{DPPH radical scavenging assay}

Quantitative measurements of radical scavenging assay were carried out according to the method described by Khirul et al. [15]. The reaction mixture contained $2 \mathrm{ml}$ of extract at concentration ranging from 1 to $512 \mu \mathrm{g} / \mathrm{ml}$ and $6 \mathrm{ml}$ of a $0.04 \%(\mathrm{w} / \mathrm{v})$ solution of DPPH in methanol. The commercial known antioxidant, ascorbic acid was used for comparison. Discolouration was measured at $517 \mathrm{~nm}$ by using spectrophotometer after incubation of $30 \mathrm{~min}$ in the darkroom. Measurement was performed at least in triplicate. The percentage of the $\mathrm{DPPH}$ free radical was calculated using the following equation:

$$
\text { DPPH scavenging effect }(\%)=\left(\left(\mathrm{A}_{0}-\mathrm{A}_{1}\right) / \mathrm{A}_{0}\right) \times 100
$$

Where, $A_{0}$ was the absorbance of the control and $A_{1}$ was the absorbance in the presence of the extract. The $\mathrm{IC}_{50}$ (concentration providing $50 \%$ inhibition) values were calculated using the dose inhibition curve in linear range by plotting the extract concentration versus the corresponding scavenging effect.

\section{Reducing power assay}

The reducing power was determined according to the method of Sanjib et al. [16]. An alequite of $1 \mathrm{ml}$ of various concentrations of extracts $(10-100 \mu \mathrm{g} / \mathrm{ml})$ were mixed with $2.5 \mathrm{ml}$ of $200 \mathrm{mmol} / \mathrm{l}$ sodium phosphate buffer $(\mathrm{pH}$ 6.6) and $2.5 \mathrm{ml}$ of $1 \%$ potassium ferricyanide. The mixture was incubated at $50{ }^{\circ} \mathrm{C}$ for $20 \mathrm{~min}$. After $2.5 \mathrm{ml}$ of $10 \%$ trichloroacetic acid was being added, the mixture was centrifuged at $3000 \mathrm{rpm}$ for $10 \mathrm{~min} .5 \mathrm{~mL}$ of this mixture was mixed with $5 \mathrm{~mL}$ of deionised water and $1 \mathrm{ml}$ of $0.1 \%$ of ferric chloride, and ten minutes later the absorbance was measured at $700 \mathrm{~nm}$. The assays were carried out in triplicate and the results were expressed as mean values \pm standard deviations. Ascorbic acid was used as standard.

\section{Hydrogen peroxide scavenging assay}

The scavenging capacity for hydrogen peroxide was measured according to the method of Rahmat et al. [17]. A solution of hydrogen peroxide $(2 \mathrm{mM})$ was prepared in $50 \mathrm{mM}$ phosphate buffer ( $\mathrm{pH}$ 7.4). Hydrogen peroxide concentration was determined spectrophotometrically at $230 \mathrm{~nm}$ absorption using the molar extinction coefficient for hydrogen peroxide of $81 \mathrm{M}^{-1} \mathrm{~cm}^{-1}$. Then $1 \mathrm{ml}$ of various concentrations $(25-250 \mu \mathrm{g} / \mathrm{ml})$ of extracts, ascorbic acid was transferred into the test tubes and their volumes were made up to $4 \mathrm{ml}$ with $50 \mathrm{mM}$ phosphate buffer ( $\mathrm{pH}$ 7.4) or solvent (methanol). After addition of $6 \mathrm{ml}$ hydrogen peroxide solution, tubes were vortexed and absorbance of the hydrogen peroxide at $230 \mathrm{~nm}$ was determined after $10 \mathrm{~min}$, against a suitable blank. $50 \mathrm{mM}$ phosphate buffer without hydrogen peroxide was used as blank. Hydrogen peroxide scavenging ability (in triplicate) was calculated by the formula:

$$
\% \text { scavenging }=\left(1-\mathrm{A}_{\mathrm{e}} / \mathrm{A}_{\mathrm{o}}\right) \times 100
$$

Where, $A_{o}$ is the absorbance without sample, and $A_{e}$ is absorbance with sample.

\section{Nitric oxide scavenging assay}

Nitric oxide scavenging activity was measured spectrophotometrically according to Usha and Suriyavathana [18]. Three millilitres of $10 \mathrm{mM}$ Sodium nitroprusside in $0.2 \mathrm{M}$ phosphate buffered saline $(\mathrm{pH} 7.4)$ was mixed with different concentrations $(5-100 \mu \mathrm{g} / \mathrm{ml})$ of extracts and incubated at room temperature for $150 \mathrm{~min}$. After incubation time, $0.5 \mathrm{ml}$ of Griess reagent ( $1 \%$ sulfanilamide, $0.1 \%$ naphthylethylene diamine dihydrochloride in $\left.2 \% \mathrm{H}_{3} \mathrm{PO}_{4}\right)$ was added. The absorbance of the chromophore formed during diazotization of the nitrite with sulphanilamide and subsequent coupling with naphthylethylenediaminedihydrochloride was read at $546 \mathrm{~nm}$. Ascorbic acid was used as standard in this study. Percentage radical scavenging activity of the sample was calculated as follows: \% NO radical scavenging activity $=($ control OD- sample OD/control OD $) \times 100$. The analysis was performed in triplicate. The sample concentration providing $50 \%$ inhibition $\left(\mathrm{IC}_{50}\right)$ under the assay condition was calculated from the graph of inhibition percentage against sample concentration.

\section{HPLC detection and quantification of polyphenolic compounds}

Chromatographic analyses were carried out on a Thermo Scientific DionexUltiMate 3000 Rapid Separation LC (RSLC) systems (Thermo Fisher Scientific Inc., MA, USA), coupled to a quaternary rapid separation pump (LPG-3400RS), Ultimate 3000RS autosamplier (WPS3000 ) and rapid separation diode array detector (DAD3000RS). Phenolic compounds were separated on Acclaim $^{\circ} \mathrm{C} 18(4.6 \times 250 \mathrm{~mm} ; 5 \mu \mathrm{m})$ column (Dionix, USA) which was controlled at $30^{\circ} \mathrm{C}$ using a temperature controlled column compartment (TCC-3000).

The phenolic composition of the leaves \& stem extract of B. gymnorrhiza was determined by HPLC, as described by Sarunya \& Sukon with some modifications [18]. The mobile phase consisted of acetonitrile (solvent A), acetic acid solution pH 3.0 (solvent B), and methanol (solvent $\mathrm{C}$ ). The system was run with the following 
gradient elution program: $0 \mathrm{~min}, 5 \% \mathrm{~A} / 95 \% \mathrm{~B} ; 10 \mathrm{~min}$, $10 \% \mathrm{~A} / 80 \% \mathrm{~B} / 10 \% \mathrm{C} ; 20 \mathrm{~min}, 20 \% \mathrm{~A} / 60 \% \mathrm{~B} / 20 \% \mathrm{C}$ and $30 \mathrm{~min}, 100 \% \mathrm{~A}$. There was a $5 \mathrm{~min}$ post run at initial conditions for equilibration of the column. The flow rate was kept constant throughout the analysis at $1 \mathrm{ml} / \mathrm{min}$ and the injection volume was $20 \mu \mathrm{l}$. For UV detection, the wavelength program was optimized to monitor phenolic compounds at their respective maximum absorbance wavelengths as follows: $\lambda 280 \mathrm{~nm}$ held for $18.0 \mathrm{~min}$, changed to $\lambda 320 \mathrm{~nm}$ and held for $6 \mathrm{~min}$, and finally changed to $\lambda 380 \mathrm{~nm}$ and held for the rest of the analysis and the diode array detector was set at an acquisition range from $200 \mathrm{~nm}$ to $700 \mathrm{~nm}$. The detection and quantification of $\mathrm{GA}, \mathrm{CH}, \mathrm{VA}, \mathrm{CA}$, and $\mathrm{EC}$ was done at $280 \mathrm{~nm}$, of PCA, RH, and EA at $320 \mathrm{~nm}$, and of MC, QU, and $\mathrm{KF}$ at $380 \mathrm{~nm}$, respectively.

A stock standard solution $(100 \mu \mathrm{g} / \mathrm{ml})$ of each phenolic compound was prepared in methanol by weighing out approximately $0.0050 \mathrm{~g}$ of the analyte into $50 \mathrm{ml}$ volumetric flask. The mixed standard solution was prepared by diluting the mixed stock standard solutions in methanol to give a concentration of $5 \mu \mathrm{g} / \mathrm{ml}$ for each polyphenols except $(+)$-catechin hydrate, caffeic acid, rutin hydrate $(4 \mu \mathrm{g} / \mathrm{ml})$ and quercetin $(3 \mu \mathrm{g} / \mathrm{ml})$. All standard solutions were stored in the dark at $5{ }^{\circ} \mathrm{C}$ and were stable for at least three months. The calibration curves of the standards were made by a dilution of the stock standards (five set of standard dilutions) with methanol to yield $1.0-5.0 \mu \mathrm{g} / \mathrm{ml}$ for $\mathrm{GA}, \mathrm{CH}, \mathrm{VA}, \mathrm{EC}$, PCA, EA, MC, KF;0.5-4.0 $\mu \mathrm{g} / \mathrm{ml}$ for $\mathrm{CH}, \mathrm{CA}, \mathrm{RH}$, and $0.25-3.0 \mu \mathrm{g} / \mathrm{ml}$ for QU. The calibration curves were constructed from chromatograms as peak area vs. concentration of standard.

Solution of ethanol extracts (leaves \& stem) of B. gymnorrhiza at a concentration of $10 \mathrm{mg} / \mathrm{ml}$ was prepared in ethanol by vortex mixing (Branson, USA) for $30 \mathrm{~min}$. The samples were stored in the dark at low temperature $\left(5{ }^{\circ} \mathrm{C}\right)$. Spiking the sample solution with phenolic standards was done for additional identification of individual polyphenols. Prior to HPLC analysis, all solutions (mixed standards, sample, and spiked solutions were filtered through $0.20 \mu \mathrm{m}$ nylon syringe filter (Sartorius, Germany) and then degassed in an ultrasonic bath (Hwashin, Korea) for 15 min [19].

\section{Analgesic activity}

Analgesic activity of the extracts was tested using the model of acetic acid induced writhing in mice [20]. The experimental laboratory mice were arbitrarily divided in six groups each containing six mice. The first group, treated as control group, was administered orally with $1 \%(\mathrm{v} / \mathrm{v})$ Tween-80 in distilled water at the dose of $10 \mathrm{ml} / \mathrm{kg}$ body weight. The second group received standard diclofenac sodium $(25 \mathrm{mg} / \mathrm{kg})$. Third to sixth groups were treated with the extract at the doses of 250 and $500 \mathrm{mg} / \mathrm{kg}$ body weight. Experimental samples, standard drug and control vehicle were administered orally $30 \mathrm{~min}$ prior to intraperitoneal administration of $0.7 \%$ of acetic acid. After an interval of $5 \mathrm{~min}$, the number of writhes was counted for a period of $15 \mathrm{~min}$. The number of writhes in the second, third, fourth, fifth and sixth groups were compared to that of the control group to calculate the percent inhibition of writhing calculated using the formula: \% Inhibition of writhing $=\left(1-\mathrm{W}_{0} / \mathrm{W}_{1}\right) \times 100$; Where, $\mathrm{W}_{1}$ and $\mathrm{W}_{0}$ represent the mean writhing of the control and standard or sample groups, respectively.

\section{Antidiarrhoeal activity}

Antidiarrhoeal activity of the extracts was assessed according to Bokshi et al. [21]. The mice were all screened initially by giving $0.3 \mathrm{ml}$ of castor oil and only those showing diarrhoea were selected for the final experiment. The test animals were randomly chosen and divided into six groups having six mice in each; they were accurately weighed \& properly marked of the experimental groups, group-I or the control received only distilled water containing $1 \%$ Tween80. Group-II or standard received standard antimotility drug, Loperamide at a dose of $3 \mathrm{mg} / \mathrm{kg}$-body weight as oral suspension. The test groups (III, IV, Vand VI) were treated with suspension of leaf and stem extracts at the oral dose of $250 \& 500 \mathrm{mg} / \mathrm{kg}$-body weight. Test samples, control and loperamide were given orally by means of a feeding needle. Individual animals of each group were placed in separate cages having adsorbent paper beneath and examined for the presence of diarrhoea every hour in four hours of experimental period. Number of stools or any fluid material that stained the adsorbent paper were counted at each successive hour during the $4 \mathrm{~h}$ period and were noted for each mouse. The latent period of each mouse also counted. At the beginning of each hour new papers were placed for the old ones. During an observation period of $4 \mathrm{~h}$, the total number of fecal output including diarrheic feces excreted by the animals was recorded. A numerical score based on stool consistency was assigned as normal stool (1) and watery stool (2).

\section{Acute toxicity test}

Acute oral toxicity of the extracts was assessed in mice according to the guidelines of the Organization for Economic Cooperation and Development [22]. The mice were fasted overnight $(16 \mathrm{~h})$, divided into 10 groups $(\mathrm{n}=5)$ and the extracts were orally administered at the dose of $100,200,400$, 800 and $1000 \mathrm{mg} / \mathrm{kg}$ body weight. The control group received distilled water. Then individual observations for lethality and any physical sign of toxicity of mice were started during the first two hours continuously and then at six hours interval for $24 \mathrm{~h}$ time period and finally after every $24 \mathrm{~h}$ up to 14 days. 


\section{Cytotoxic activity}

Cytotoxic activity of extracts was carried out according to the Meyer method [23]. Artemia salina leach (brine shrimp eggs) was used as the test organism. It was hatched in simulated sea water. Two days were allowed to hatch the shrimp and to be matured as nauplii. Constant oxygen supply was carried out through the hatching time. For the experiment, $50 \mathrm{mg}$ of the extracts was dissolved in dimethylsulfoxide (DMSO) and solutions of varying concentrations $(400,200,100,50,25,12.5,6.25$, $3.125,1.563,0.781 \mu \mathrm{g} / \mathrm{ml}$ ) were prepared using simulated seawater. The concentration of DMSO in these test tubes did not exceed $10 \mu \mathrm{l} / \mathrm{ml}$. The solutions were then added to the pre-marked vials containing 10 live brine shrimp nauplii in $5 \mathrm{ml}$ simulated seawater. After $24 \mathrm{~h}$, the vials were inspected and the number of survived nauplii in each vial was counted. From this data, the percent of lethality of the brine shrimp nauplii for each concentration of extracts and control was calculated. The lethal concentration $\mathrm{LC}_{50}$ of the test samples after $24 \mathrm{~h}$ was obtained by a plot of percentage of the shrimps killed against the sample concentration (toxicant concentration) and the best fit line was obtained from the curve data by means of regression analysis. In this assay vincristin sulfate was used as standard.

\section{Statistical analysis}

One-way ANOVA followed by Dunnett's test were performed and the results were considered statistically significant when $p<0.05$. Data acquisition, peak integration, and calibrations in HPLC were performed with Dionix Chromeleon software (Version 6.80 RS 10).

\section{Results}

In the phytochemical screening the extracts revealed the presence of some of the therapeutically active phytochemicals. Leaves extract showed the presence of anthraquinone glycosides, flavonoids, alkaloids, tannin, saponins and absence of terpenoid and gum. One the other hand, anthraquinone glycosides, flavonoids, alkaloids, tannin, saponins and gum were present and terpenoid was absent in the stem extract.

The absorbance values of different concentrations of gallic acid were plotted and a standard calibration curve $\left(y=8.8234 x+0.1616 ; R^{2}=0.9933\right)$ was found. The total polyphenol content of the stem and leaf extract was calculated using the equation and was found to be $40 \mathrm{mg}$ and $33 \mathrm{mg} \mathrm{GAE} / \mathrm{g}$ of dry extract respectively. Standard quercetin calibration curve $\left(y=0.5034 x+0.0075 ; R^{2}=\right.$ 0.9816) was used to estimate the total flavonoid content. And it was found to be 23 and 17 milligram quercetin equivalents per gram of the dry weight of stem and leaf extract respectively.

Identification and quantification of individual phenolic compounds in the extracts were analysed by HPLC. The chromatographic separations of polyphenols in standard and leaf and stem extract were shown in Figs. 1, 2 and 3 respectively. The content of each phenolic compound found in the leaf and stem extracts was calculated from the corresponding calibration curve and presented as the mean of five determinations as shown in Tables 1 and 2. The experimental results indicated that leaf extract contained gallic acid, vanillic acid, vanillin and ellagic acid whereas stem extract contained gallic acid, (+)-catechin, vanillic acid, vanillin, ellagic acid and

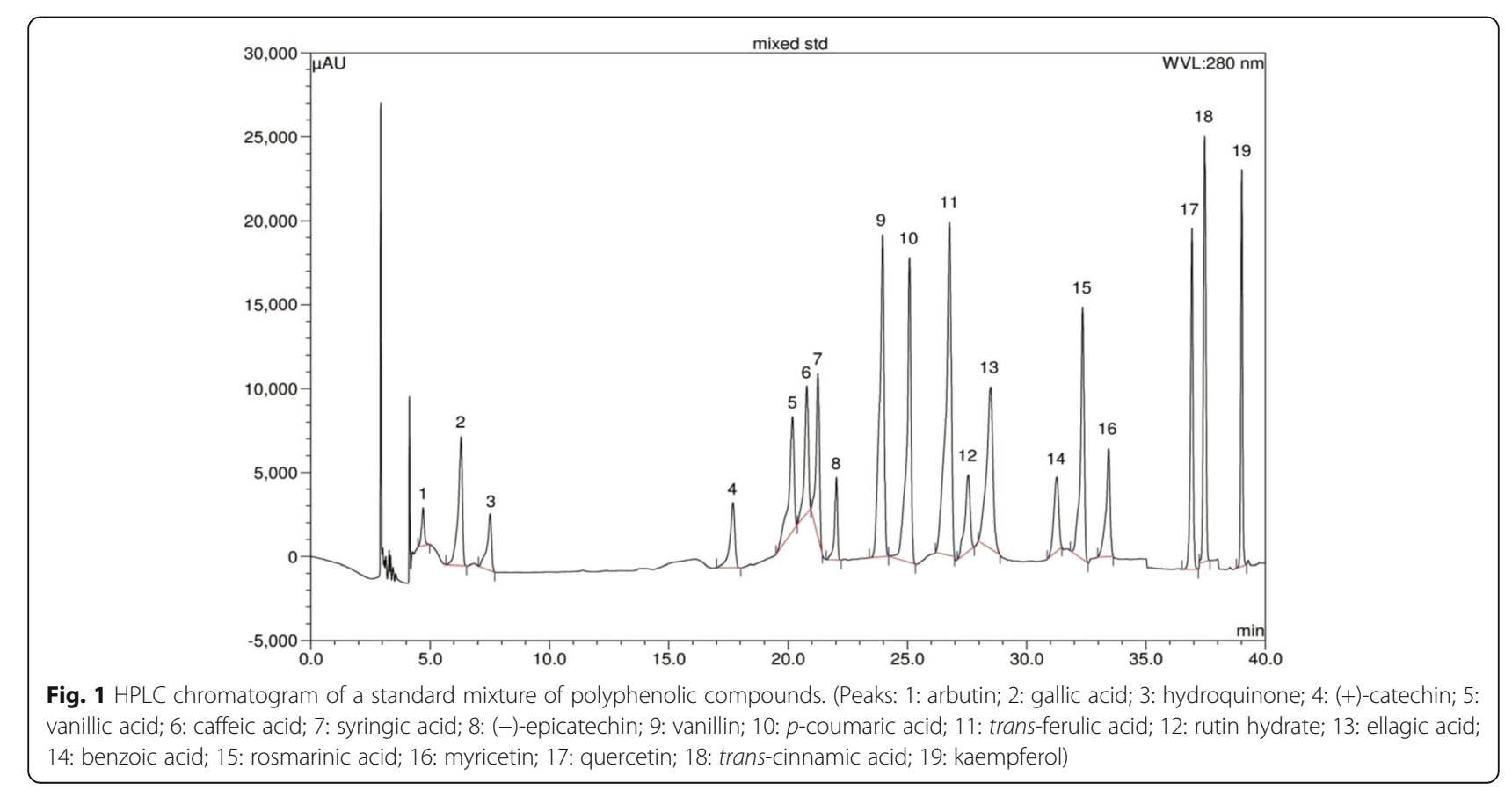




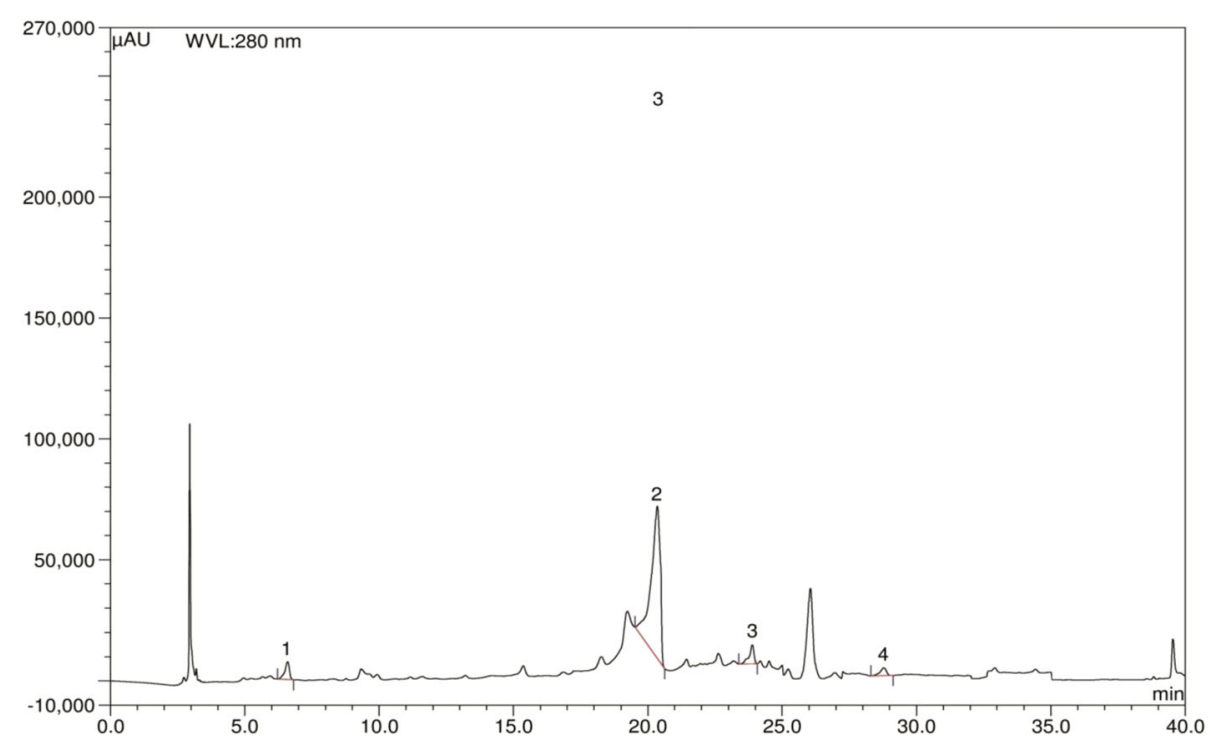

Fig. 2 HPLC chromatogram of leaf extract. (Peaks: 1: gallic acid; 2: vanillic acid; 3: vanillin; 4: ellagic acid)

benzoic acid. Among these compounds vanillic acid was found the highest in both extracts.

\section{DPPH radical scavenging assay}

In the DPPH free radical scavenging assay the $\mathrm{IC}_{50}$ values of leaf and stem were found to be $\sim 73 \& \sim 62 \mu \mathrm{g} /$ $\mathrm{ml}$ respectively that were comparable to standard ascorbic acid $\left(\mathrm{IC}_{50}=\sim 14 \mu \mathrm{g} / \mathrm{ml}\right)$.

\section{Hydrogen peroxide scavenging assay}

In the hydrogen peroxide scavenging assay the $\mathrm{IC}_{50}$ value of ascorbic acid, leaf and stem were found to be $\sim 45, \sim 174 \& \sim 130 \mu \mathrm{g} / \mathrm{ml}$ respectively.

\section{Nitric oxide scavenging activity}

In the nitric oxide scavenging assay the $\mathrm{IC}_{50}$ value of ascorbic acid, leaf and stem were found to be $\sim 17, \sim 97$ \& $\sim 57 \mu \mathrm{g} / \mathrm{ml}$ respectively.

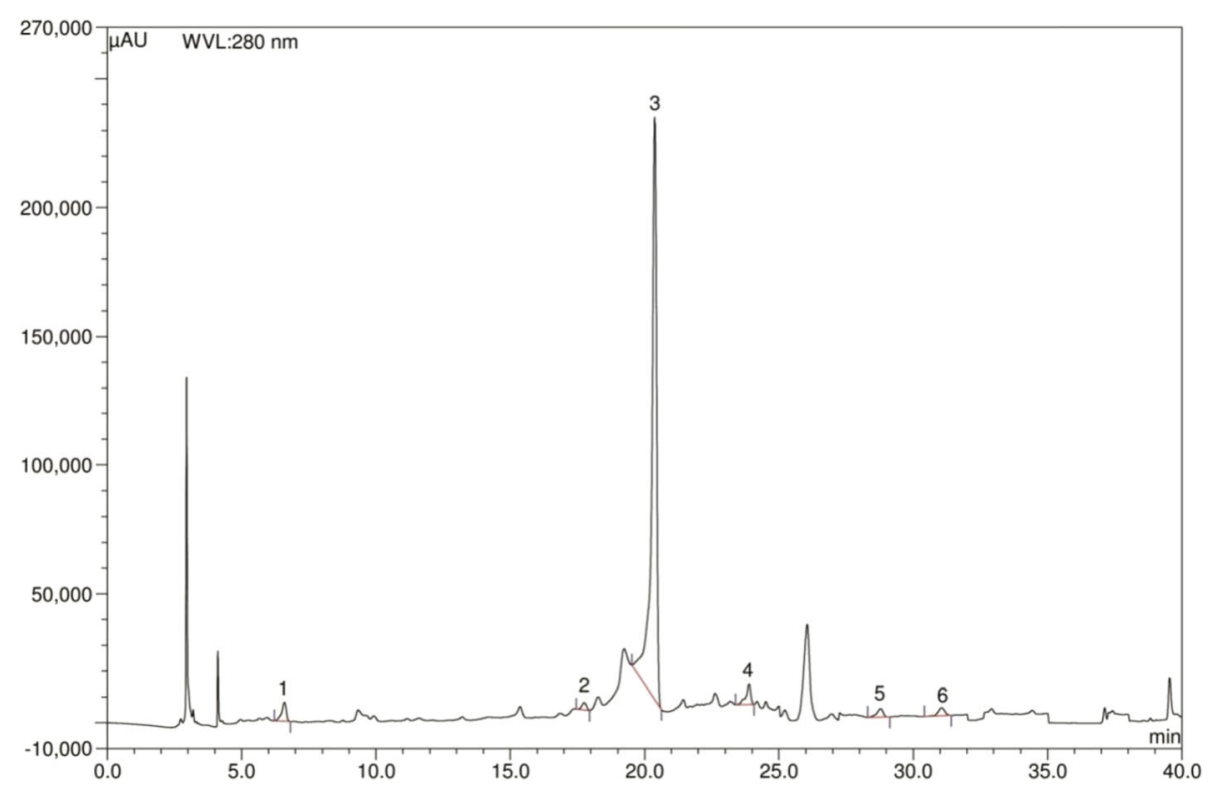

Fig. 3 HPLC chromatogram of stem extract. (Peaks:1: gallic acid; 2: (+)-catechin; 3: vanillic acid; 4: vanillin; 5: ellagic acid; 6: benzoic acid) 
Table 1 Contents of polyphenolic compounds in the ethanol extract of leaf

\begin{tabular}{lcc}
\hline $\begin{array}{l}\text { Polyphenolic } \\
\text { compound }\end{array}$ & Ethanol extract of leaf & \\
\cline { 2 - 3 } & Content $(\mathrm{mg} / 100 \mathrm{~g}$ of dry extract) & $\%$ RSD \\
\hline GA & 7.25 & 0.07 \\
VA & 68.47 & 1.19 \\
VL & 10.09 & 0.11 \\
EA & 36.22 & 0.25 \\
\hline
\end{tabular}

RSD Relative Standard Deviation

\section{Reducing power assay}

At the concentrations of 10, 20, 40, 60, 80 and $100 \mu \mathrm{g} /$ $\mathrm{mL}$ leaf and stem extract showed absorbance of 0.094, $0.108,0.137,0.186,0.196,0.217$ and $0.127,0.147,0.194$, $0.237,0.295,0.327$ respectively while standard ascorbic acid showed absorbance of 0.493, 0.509, 0.518, 0.601, 0.648 , and 0.684 respectively.

\section{Analgesic activity}

The leaves extract used orally at different doses $(250 \mathrm{mg} / \mathrm{kg}$ and $500 \mathrm{mg} / \mathrm{kg})$ showed significant $(p<0.01)$ and dose dependent inhibition of pain responses $(32.55$ and $59.09 \%$ respectively) as compared to control group. On the other hand the stem extract at the dose of 250 and $500 \mathrm{mg} / \mathrm{kg}$ showed significant $(p<0.01)$ inhibition of pain responses (40.19 and $65.91 \%$ respectively) whereas standard diclofenac sodium $(25 \mathrm{mg} / \mathrm{kg})$ showed $80.27 \%$ writhing inhibition (Table 3 ). The stem extract showed more significant writhing inhibition in comparison to leaves extract.

\section{Antidiarrhoeal activity}

In the castor oil induced diarrhoeal method, the leaves and stem extracts of B. gymnorrhiza produced a marked antidiarrhoeal effect in mice, as shown in Table 4. Thirty minutes after castor oil administration, all of the mice in the control group produced copious diarrhea. Pretreatment of mice with both the leaves and stem extract $(250,500 \mathrm{mg} /$ $\mathrm{kg}$, p.o.) dose dependently and significantly $(p<0.01)$ delayed the onset of diarrhea and reduced the frequency of

Table 2 Contents of polyphenolic compounds in the ethanol extract of stem

\begin{tabular}{lcc}
\hline $\begin{array}{l}\text { Polyphenolic } \\
\text { compound }\end{array}$ & Ethanol extract of stem & \\
\cline { 2 - 3 } & Content $(\mathrm{mg} / 100 \mathrm{~g}$ of dry extract) & $\%$ RSD \\
\hline GA & 8.91 & 0.08 \\
CH & 6.05 & 0.05 \\
VA & 132.51 & 2.41 \\
VL & 11.64 & 0.13 \\
EA & 39.22 & 0.29 \\
BA & 19.83 & 0.16 \\
\hline RSD Relative Standard Deviation & &
\end{tabular}

RSD Relative Standard Deviation
Table 3 Effect of extracts in acetic acid induced writhing in mice

\begin{tabular}{llll}
\hline Treatment & $\begin{array}{l}\text { Dose } \\
(\mathrm{mg} / \mathrm{kg})\end{array}$ & $\begin{array}{l}\% \\
\text { Writhing }\end{array}$ & $\begin{array}{l}\text { \% Inhibition of } \\
\text { writhing }\end{array}$ \\
\hline Control & - & 100 & - \\
Standard & 25 & 19.73 & $80.27 \pm 0.52^{*}$ \\
Leaf extract & 250 & 67.45 & $32.55 \pm 0.58^{*}$ \\
Leaf extract & 500 & 40.91 & $59.09 \pm 0.45^{*}$ \\
Stem extract & 250 & 59.81 & $40.19 \pm 0.58^{*}$ \\
Stem extract & 500 & 34.09 & $65.91 \pm 0.52^{*}$ \\
\hline
\end{tabular}

$S D$ standard deviation; ${ }^{*} p<0.01$

defecation (Table 4). But the stem extract was more potent than leaves extract regarding the latent period and frequency of stool. Loperamide (3 $\mathrm{mg} / \mathrm{kg})$, a standard anti diarrhoeal drug markedly $(p<0.01)$ inhibited the diarrhoea.

\section{Acute toxicity test}

The oral acute toxicity assessment of the extract at 100, 200, 400, 800 and $1000 \mathrm{mg} / \mathrm{kg}$ body weight resulted in no mortality and no observable signs of acute toxicity throughout 14 days. These results pointed out that the $\mathrm{LC}_{50}$ (lethal concentration in 50\%) value of the extract was greater than $1000 \mathrm{mg} / \mathrm{kg}$ body weight.

\section{Brine shrimp lethality bioassay}

The cytotoxic activity of stem and leaves extracts of $B$. gymnorrhiza assayed by the brine shrimp lethality bioassay test. The effect of the extract was dose dependent. In this assay the leaves and stem extracts showed $\mathrm{LC}_{50}$ value of $201.31 \mu \mathrm{g} / \mathrm{ml}$ and $232.09 \mu \mathrm{g} / \mathrm{ml}$ respectively whereas standard vincristine sulphate showed $\mathrm{LC}_{50}$ value of $0.7158 \mu \mathrm{g} / \mathrm{ml}$. No mortality was found in control group.

\section{Discussion}

Bruguiera gymnorrhiza is ethnopharmacologically used for the treatment of various complaints. The therapeutic benefit of medicinal plants is usually attributed to their antioxidant properties. Phenolic compounds are known as high level antioxidants because of their ability to

Table 4 Effect of leaf and stem extract on the latent period and of mean stool count of castor oil induced diarrhoeal episode in mice

\begin{tabular}{llll}
\hline Treatment & $\begin{array}{l}\text { Dose } \\
(\mathrm{mg} / \mathrm{kg})\end{array}$ & $\begin{array}{l}\text { Mean Latent } \\
\text { period }(\mathrm{hr})\end{array}$ & $\begin{array}{l}\text { Mean no. of } \\
\text { stools }\end{array}$ \\
\hline 1\% Tween 80 in water & - & $0.47 \pm 0.03$ & $5.66 \pm 0.82$ \\
Standard & 3 & $2.85 \pm 0.07^{*}$ & $2.17 \pm 0.75^{*}$ \\
Leaf extract & 250 & $0.58 \pm 0.06^{*}$ & $4.67 \pm 0.52^{* *}$ \\
Leaf extract & 500 & $0.97 \pm 0.14^{*}$ & $4 \pm 0.89^{*}$ \\
Stem extract & 250 & $1.00 \pm 0.14^{*}$ & $3.83 \pm 0.75^{*}$ \\
Stem extract & 500 & $2.48 \pm 0.18^{*}$ & $3 \pm 0.89^{*}$ \\
\hline SD Standard & & &
\end{tabular}

SD Standard Deviation; ${ }^{*} P<0.01 ;{ }^{* *} P<0.05$ 


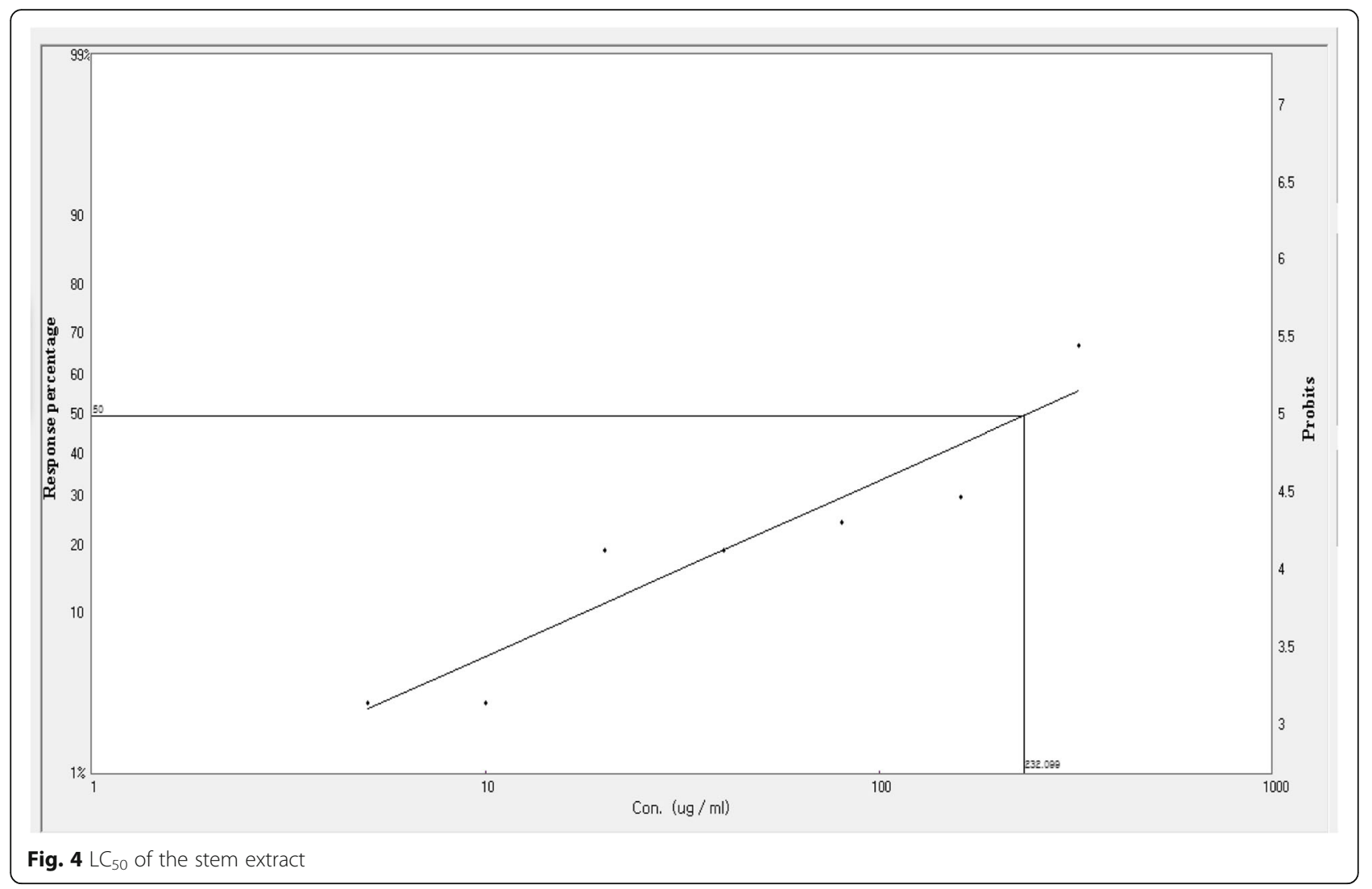

scavenge free radicals and active oxygen species such as singlet oxygen, superoxide anion radical and hydroxyl radicals $[24,25]$. The structure as well as number and position of hydroxyl groups in polyphenols are essential for antioxidant activity [26-28]. The total polyphenol concentration of extract includes in addition to the principal phenolic antioxidants all the compounds that function as hydrogen donors in the plant material. Both extracts of B. gymnorrhiza contain significant amount of polyphenols and consequently significant antioxidant capacity found. Moreover, HPLC analyses of the both extracts indicate the presence of natural polyphenolic antioxidant compounds and it is supposed that these polyphenolic compounds may be responsible for antioxidant activity of the leaf and stem extract.

Analgesic activity of the both extracts was evaluated by acetic acid-induced writhing method that is the most sensitive and established method to assess analgesia. A few numbers of analgesics have been isolated from plants and thus require extensive studies to explore more analgesic agents from natural sources. Increased levels of local endogenous substances; PGE2, PGF2 $\alpha$ as well as lipoxygenase derived eicosanoids in the peritoneal fluid have been reported to be responsible for pain sensation caused by intraperitoneal administration of acetic acid [29-31]. The writhing inhibition in mice increased as concentration of the extracts was increased. From the present study it can be stated that stem extracts both at 250 and $500 \mathrm{mg}$ per $\mathrm{kg}$ body weight were more potent than that of leaf (Table 3) as former produced remarkable writhing inhibition which was comparable to the standard diclofenac sodium. It is well established that various favonoids, alkaloids, steroids are involved in analgesic activity [32, 33]. In the phytochemical group tests of leaf extract, some major phytochemicals namely; alkaloids, steroids, glycosides, tannins, and flavonoids were identified whereas glycosides, flavonoids, alkaloids, tannin, saponins and gum were present in the stem extract. Besides, polyphenolic constituents namely $(+)$-catechin, ellagic acid and vannilin identified in the HPLC analysis, which showed analgesic activity in previous studies [34,35]. Presence of slight increased amount of polyphenols as well as their synergistic action in stem extract may be responsible for more potent as an analgesic agent than other extracts.

Diarrhea can be described as the abnormally frequent defecation of feces of low consistency which may be due to a disturbance in the transport of water and electrolytes in the intestines. Although it is evidenced that ricinoleic acid produces diarrhea, recent study claims that nitric oxide in castor oil is responsible for the diarrheal effect [36, 37]. After oral ingestion of castor oil, 


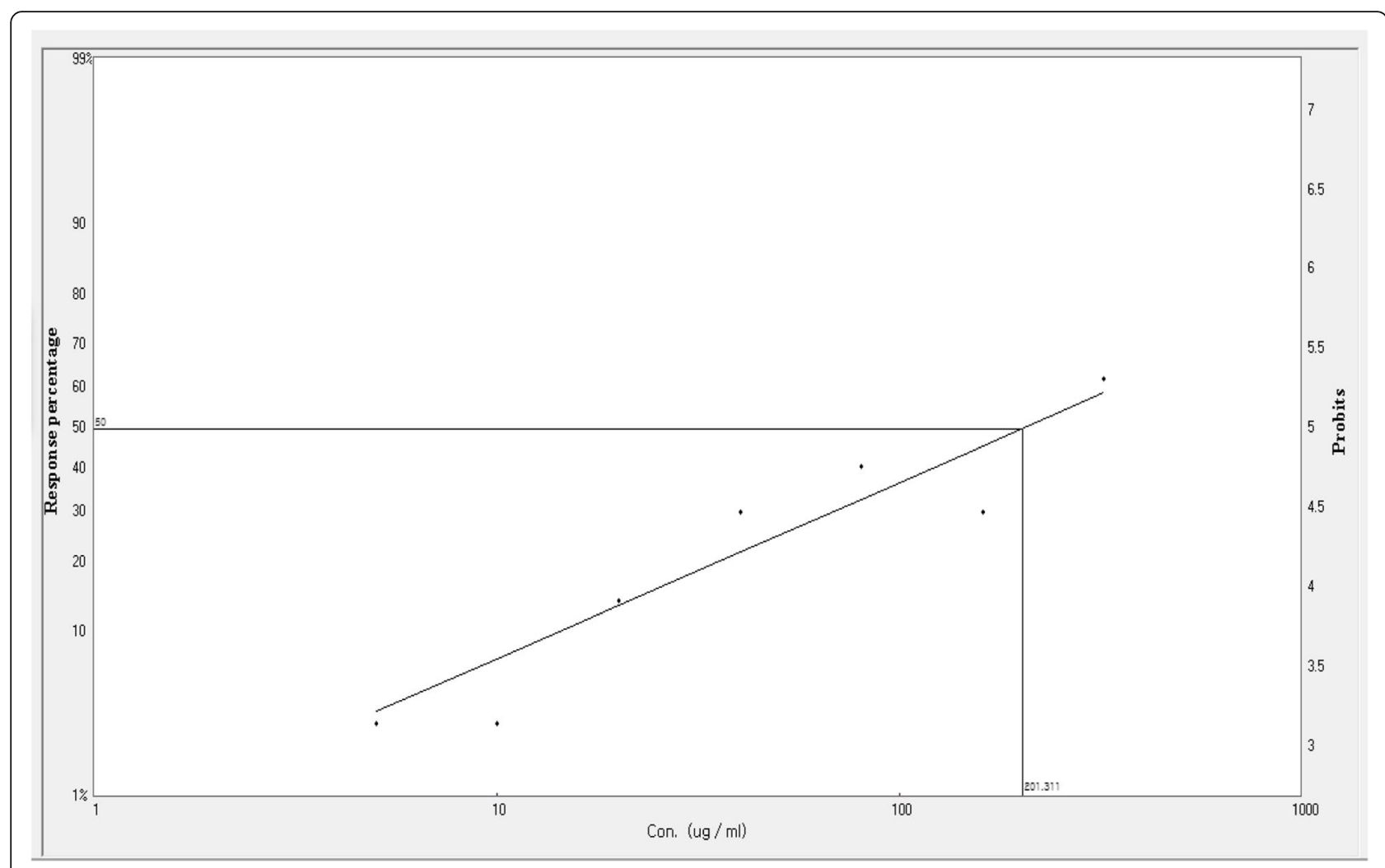

Fig. $\mathbf{5} L C_{50}$ of the leaf extract

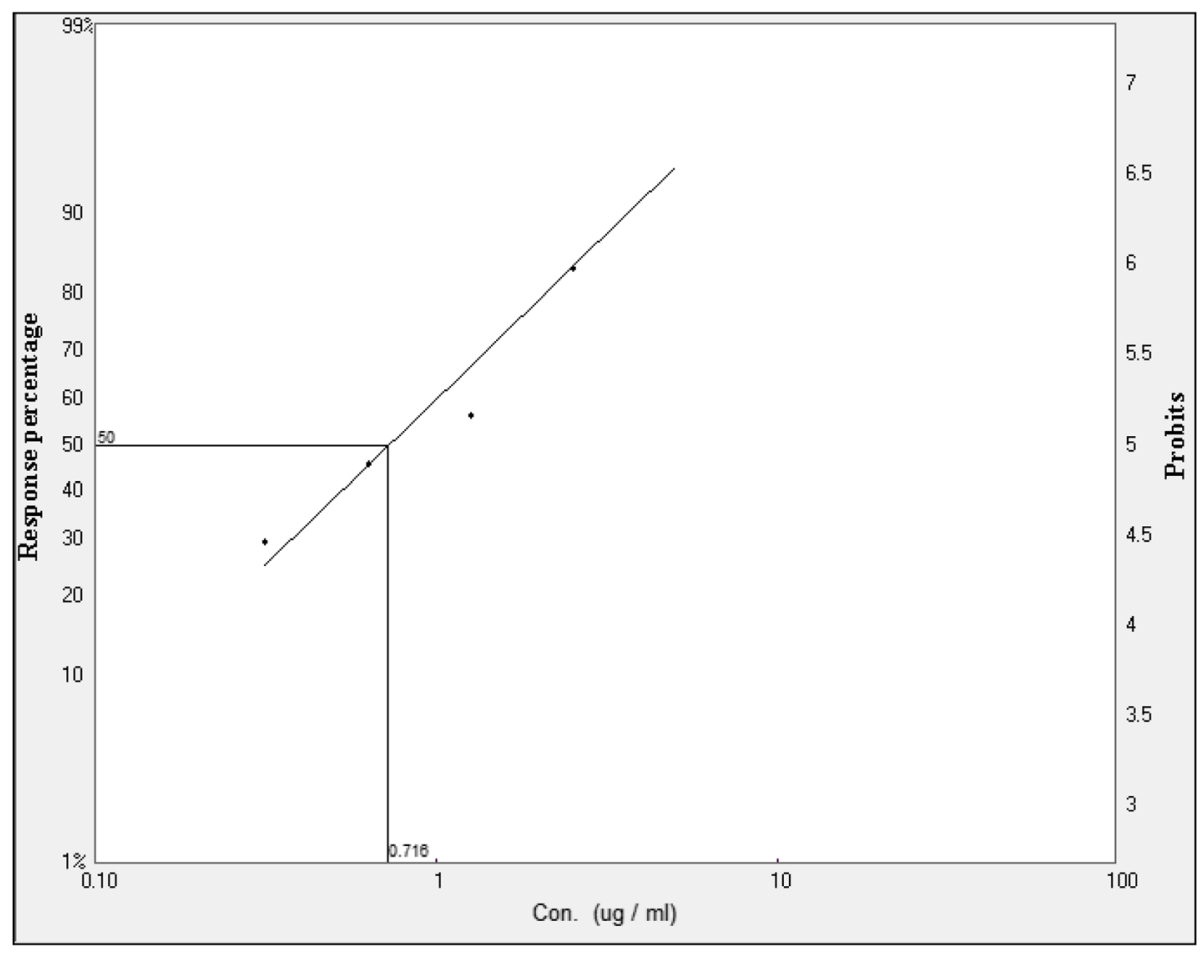

Fig. $6 L C_{50}$ of the standard vincristine sulphate 
ricinoleic acid is released by lipases in the intestinal lumen, which causes irritation and inflammation in the intestinal mucosa, resulting in the release of inflammatory mediators (e.g., prostaglandins especially PGE series and histamine) $[38,39]$. These mediators initiate vasodilatation, smooth muscle contraction, and mucus secretion in the small intestines. Also inhibition of intestinal $\mathrm{Na}+\mathrm{K}+$ ATPase activity, activation of adenylate cyclase and mucosal cAMP-mediated active secretion are the proposed mechanisms of diarrheal effect of castor oil [36]. Both the leaf and stem extracts of B. gymnorrhiza were found to inhibit the severity of diarrhoea induced by castor oil. The onset of diarrhea and frequency of defecation was reduced in dose dependent manner. Between the extracts, the stem extract was more potent than leaves extract regarding the latent period and frequency of stool. Antidiarrhoeal activity of tannins, flavonoids, polyphenols, saponins, alkaloids, sterols, reducing sugars and triterpenes was reported previously [40-42]. In the phytochemical group tests alkaloids, glycosides, tannins, and flavonoids were identified in both extracts. In addition to, (+)-catechin, ellagic acid, gallic acid and vannilin identified in the HPLC analysis, inhibited prostaglandins and consequently showed antidiarrhoel activity reported in previous studies [43, 44].

Most studies of polyphenols aimed to determine the protective effects of polyphenols against diseases and relatively few investigators have examined their possible toxicity. No acute toxicity was observed after oral administration of a grape seed proanthocyanidin extract at a dose of $2 \mathrm{~g} / \mathrm{kg}$ and punicalagin (an ellagitannin present in pomegranate juice) at a dose of $60 \mathrm{~g} / \mathrm{kg}$ body weight to rats or mice $[45,46]$. Controversial results also have been reported in previous studies $[45,47,48]$. The risk of consuming high doses of polyphenols from naturally polyphenol rich foods is low. From our result of acute toxicity it can be supposed that both extracts were safe at high dose ( $1 \mathrm{~g} / \mathrm{kg}$ body weight).

The brine shrimp lethality assay was considered as a convenient method for preliminary assessment of toxicity. It can also be used to extrapolate cell line toxicity and antitumor activity [36]. B. gymnorrhiza extracts were assessed for their cytotoxicity using the sensitive in vitro brine shrimp lethality bioassay (Figs. 4, 5 and 6). The leaves and stem extracts showed $\mathrm{LD}_{50}$ value of $201.31 \mu \mathrm{g} / \mathrm{ml}$ and $232.09 \mu \mathrm{g} / \mathrm{ml}$ respectively. From the present study, it can be well predicted that the extracts do not have considerable cytotoxic activity.

\section{Conclusion}

The crude ethanol extracts of the leaf and stem of Bruguiera gymnorrhiza revealed significant antioxidant, analgesic and antidiarrhoeal activities. The observed pharmacological activities may be due to the presence of significant concentration of vanillic acid in the plant extracts. In addition, individual or synergistic activity of other phenolic constituents present in the extracts might be responsible for these pharmacological activities. Further pharmacological investigation and bioactivity guided studies are required to isolate the active principle (s) responsible for these activities.

\section{Abbreviations}

DAD: Diode array detector; DPPH; 2: 2-diphenyl-1-picryldydrazyl; GAE: Gallic acid equivalent; HPLC: High performance liquid chromatography; $\mathrm{I}_{50}$ : $50 \%$ Inhibitory concentration; $\mathrm{LC}_{50}$ : Lethal concentration in $50 \%$ test animal; OD: Optical density; QE: Quercetin equivalent; $R^{2}$ : Coefficient of determination; RSD: Relative standard deviation

\section{Acknowledgements}

The authors are grateful to the authority of International Centre for Diarrhoeal Disease and Research, Bangladesh (ICDDR, B) for providing experimental mice.

\section{Funding}

Not applicable.

\section{Availability of data and materials}

The datasets supporting the conclusions of this article are included within the article.

\section{Authors' contributions}

This work has been carried out in collaboration among authors. IM and $\mathrm{MNHZ}$ have performed the extraction, antioxidant and other pharmacological activities. NNB and BB managed the literature searches, performed phytochemical screening, HPLC analysis and carried out the statistical analysis. BB designed the study. BB and $\mathrm{MNHZ}$ drafted the manuscript. All authors read and approved the final manuscript.

\section{Competing interests}

The authors declare that they have no competing interests.

\section{Consent for publication}

Not applicable.

\section{Ethics approval}

In our study, Organization for Economic Cooperation and Development guidelines for the care and use of animals were followed. Our study was approved by a research Ethics Committee for Animal House of Pharmacy Discipline, Life Science School, Khulna University, Khulna-9208, Bangladesh. Three members ethics committee consists of Dr. Ashis Kumar Das, Professor and chairman of the committee (dasasish03@yahoo.com), Dr. jamil Ahmed Shilpi (jamilshilpi@yahoo.com), Professor and Dr. Sheikh Jamal Uddin, Associate Professor (uddinsj@yahoo.com); Pharmacy Discipline, Life Science School, Khulna University, Khulna-9208, Bangladesh.

\section{Publisher's Note}

Springer Nature remains neutral with regard to jurisdictional claims in published maps and institutional affiliations.

Received: 27 February 2017 Accepted: 13 May 2017

Published online: 23 May 2017

\section{References}

1. Phang CW, Malek SN, Ibrahim H. Antioxidant potential, cytotoxic activity and total phenolic content of Alpinia pahangensis rhizomes. BMC Complement Altern Med. 2013;13:243. doi:10.1186/1472-6882-13-243.

2. Doss A. Preliminary phytochemical screening of some Indian medicinal plants. Ancient Sci Life. 2009;29(2):12-6.

3. Balaji G, Chalamaiah M, Ramesh B, Amarnath YR. Antidiarrhoeal activity of ethanol and aqueous extracts of Carum copticum seeds in experimental rats. Asian Pac J Trop Biomed. 2012. doi:10.1016/S2221-1691(12)60376-1. 
4. Coe FG, Anderson GJ. Screening of medicinal plants used by the Gar'funa of eastern Nicaragua for bioactive compounds. J Ethnopharmacol. 1996;53:29-50.

5. Hassan MM, Khan SA, Shaikat AH, Hossain ME, Hoque MA, Ullah MH, et al. Analgesic and anti-inflammatory effects of ethanol extracted leaves of selected medicinal plants in animal model. Vet World. 2013;6(2):68-71. doi:10.5455/vetworld.2013.68-71.

6. Azam MNK, Rahman MM, Biswas S, Ahmed MN. Appraisals of Bangladeshi medicinal plants used by folk medicine practitioners in the prevention and management of malignant neoplastic diseases. Int Scholarly Res Not. 2016. doi:10.1155/2016/7832120.

7. Tumpa SI, Hossain MI, Ishika T. Ethnomedicinal uses of herbs by indigenous medicine practitioners of Jhenaidah district, Bangladesh. J Pharmacogn Phytochem. 2014;3(2):23-33.

8. Shaikh JU, Grice ID, Tiralongo E. Cytotoxic effects of Bangladeshi medicinal plant extracts. Evid Based Complement Alternat Med. 2011. doi:10.1093/ecam/nep111.

9. Li H, Xueshi H, Sattler I, Dahse HM, Hongzheng F, Grabley S, Wenhan L. Three new pimaren diterpenoids from marine mangrove plant, Bruguiera gymnorrhiza. Pharmazie. 2005;60:705-7. doi:10.1002/chin.200601187.

10. Li H, Xueshi H, Isabel S, Moellmann U, Hongzheng F, Wenhan L, et al. New aromatic compounds from the marine mangrove Bruguiera gymnorrhiza. Planta Med. 2005;71:160-4. doi:10.1055/s-2005-837784.

11. Xiang-Xi Y, Jia-Gang D, Cheng-Hai G, Xiao-Tao H, Fei L, Zhi-Ping W, Er-Wei $H$, Yan X, Zheng-Cai D, Hui-Xue H, Ri-Ming H. Four new cyclohexylideneacetonitrile derivatives from the hypocotyl of mangrove (Bruguiera gymnorrhiza). Molecules. 2015;20:14565-75.

12. Ghani A. Practical phytochemistry. Dhaka: Parash Publishers; 2005.

13. Zilani MNH, Amirul MI, Sharmin SK, Jamil AS, Mustafizur MR, Golam MH. Analgesic and antioxidant activities of Colocasia fallax. Orient Pharm Exp Med. 2016;16:131-7. doi:10.1007/s13596-016-0222-1.

14. Anisuzzman M, Nazmul MHZ, Sharmin SK, Asaduzzman M, Golam MH Antioxidant, antibacterial potential and HPLC analysis of Dioscorea alata bulb. Indonesian J Pharm. 2016;27(1):9-14.

15. Salma AS, Siraj MA, Hossain A, Mia MS, Afrin S, Rahman MM. Investigation of the key pharmacological activities of Ficu sracemosa and analysis of its major bioactive polyphenols by HPLC-DAD. Evid Based Complement Altern Med. 2016. doi:10.1155/2016/3874516.

16. Sanjib S, Jamil AS, Himangsu M, Royhan G, Morsaline B, Lutfun N, et al. Bioactivity studies on Musa seminifera Lour. Pharmacogn Mag. 2013;9:315-22. doi:10.4103/0973-1296.117827.

17. Rahmat AK, Muhammad RK, Sumaira S, Mushtaq A. Evaluation of phenolic contents and antioxidant activity of various solvent extracts of Sonchus asper (L.) Hill. Chem Cent J. 2012;6:12.

18. Usha V, Suriyavathana M. Free radical scavenging activity of ethanolic extract of Desmodium gangeticum. J Acute Med. 2012;2:36-42.

19. Khirul MI, Nripendra NB, Sanjib S, Hemayet H, Ismet AJ, Tanzir AK, et al. Antinociceptive and antioxidant activity of Zanthoxylum budrunga Wall (Rutaceae) Seeds. Sci World J. 2014. doi:10.1155/2014/869537.

20. Islam MA, Ahmed F, Das AK, Bachar SC. Analgesic and anti-inflammatory activity of Leonurus sibiricus. Fitoterapia. 2005;76:359-62.

21. Bishwajit B, Nazmul MHZ, Aparajita M, Debendra NR, Jamil AS, Samir KS. Study of analgesic and antidiarrhoeal activities of sonneratia caseolaris (linn.) Leaf and stem using different solvent system. Indonesian J Pharm. 2013;24:255-60.

22. Abdulwali A, Jamaludin M, Khalijah A, Jamil AS, Aditya A. Evaluation of antidiabetic and antioxidant properties of Brucea javanica seed. Sci World J. 2014. doi:10.1155/2014/786130.

23. Meyer BN, Ferrigni NR, Putnum JE, Jacobson LB, Nicholos DE, McLaugline JL. Brine shrimp: a convenient general bioassay for active plant constituents. Planta Med. 1982:45:31-4.

24. Kanti BP, Syed IR. Plant polyphenols as dietary antioxidants in human health and disease. Oxid Med Cell Longev. 2009;2:270-8. doi:10.4161/oxim.2.5.9498.

25. Dejan ZO, Neda MM, Marina MF, Slobodan SP, Emilija ĐJ. Antioxidant activity relationship of phenolic compounds in Hypericum perforatum $\mathrm{L}$. Chem Cent J. 2011;5:34. doi:10.1186/1752-153X-5-34.

26. Bendary E, Francis RR, Ali HMG, Sarwat MI, Hady SE. Antioxidant and structure-activity relationships (SARs) of some phenolic and anilines compounds. Ann Agric Sci. 2013;58(2):173-81.

27. Rong T. Chemistry and biochemistry of dietary polyphenols. Nutrients. 2010;2:1231-46. doi:10.3390/nu2121231.

28. Małgorzata M, Irena P. Antioxidant activity of the main phenolic compounds isolated from hot pepper fruit (Capsicum annuum L.). J Agric Food Chem. 2005;53:1750-6.
29. Himangsu M, Sanjib S, Khalijah A, Hemayet H, Abdulwali A, Khirul MI, et al Central-stimulating and analgesic activity of the ethanolic extract of Alternanthera sessilis in mice. BMC Complement Altern Med. 2014:14:398. doi:10.1186/1472-6882-14-398.

30. Dhara AK, Suba V, Sen T, Pal S, Chaudhuri AK. Preliminary studies on the anti-inflammatory and analgesic activity of methanolic fraction of the root of Tragia involucrate. J Ethnopharmacol. 2000;72:265-8.

31. Shafiur R. Antioxida nt, analgesic, cytotoxic and antidiarrh eal activities of ethanolic Zizyphus mauritiana bark extract. Orient Pharm Exp Med. 2012;12: 67-73. doi:10.1007/s13596-011-0042-2.

32. Kumar S, Pandey AK. Chemistry and biological activities of flavonoids: an overview. Sci World J. 2013. doi:10.1155/2013/162750.

33. Bhaskar VH, Balakrishnan N. Analgesic, anti-infammatory and antipyretic activities of Pergularia daemia and Carissa carandas. DARU J Pharm Sci. 2009:17:168-74.

34. Cássia C, Thacyana TC, Miriam SNH, Felipe AP, Victor F, Marília FM, et al. Vanillic acid inhibits inflammatory pain by inhibiting neutrophil recruitment, oxidative stress, cytokine production, and NFKB activation in mice. J Nat Prod. 2015;78:1799-08. doi:10.1021/acs.jnatprod.5b00246.

35. Yrbas ML, Morucci F, Alonso R, Gorzalczany S. Pharmacological mechanism underlying the antinociceptive activity of vanillic acid. Pharmacol Biochem Behav. 2015;132:88-95. doi:10.1016/j.pbb.2015.02.016.

36. Khalilur MR, Soumitra B, Fokhrul MI, Rafikul MI, Sayeed MA, Shahnaj P, et al. Studies on the anti-diarrheal properties of leaf extract of Desmodium puchellum. Asian Pac J Trop Biomed. 2013;3:639-43.

37. Khalilur MR, Ashraf MUC, Taufiqual MI, Anisuzzaman MC, Erfan MU, Chandra DS. Evaluation of antidiarrheal activity of methanolic extract of Maranta arundinacea linn. Leaves. Adv Pharmacol Sci. 2015. doi:10.1155/2015/257057.

38. Qnais EY, Elokda AS, Abu Ghalyun YY, Abdulla FA. Antidiarrheal activity of the aqueous extract of Punica granatum (Pomegranate) peels. Pharm Biol. 2007:45:715-20.

39. Balaji G, Chalamaiah M, Ramesh B, Amarnath RY. Antidiarrhoeal activity of ethanol and aqueous extracts of Carum copticum seeds in experimental rats. Asian Pac J Trop Biomed. 2012;2(2):S1151-55.

40. Ibrahim OMS, Shwaysh MM. Evaluation of Punica granatum peels extracts and its phenolic, alkaloid and terpenoid constituents against chemically induced diarrhoea in rats. Adv Anim Vet Sci. 2016:4:161-8. doi:10.14737/ journal.aavs/2016/4.3.161.168

41. Chanchal NR, Balasubramaniam A, Sayyed N. Antidiarrheal potential of Tabernaemontana divaricata. Phytopharmacology. 2013;4:61-8.

42. Ezeigbo II, Ezeja MI, Madubuike KG, Ifenkwe DC, Ukweni IA, Udeh NE, Akomas SC. Antidiarrhoeal activity of leaf methanolic extract of Rauwolfia serpentine. Asian Pac J Trop Biomed. 2012;2:430-2.

43. Ihekwereme CP, Erhirhie EO, Mbagwu IS, Ilodigwe EE, Ajaghaku DL, Okoye FB. Antidiarrheal property of Napoleona imperialis may be due to procyanidins and ellagic acid derivatives. J App Pharm Sci. 2016;6:101-6.

44. Hai-Tao X, Siu-Wai T, Hong-Yan Q, Franky FK, Choia ZY, Quan-Bin H, Hu-Biao C, Hong-Xi X, Hong S, Ai-Ping L, Zhao-Xiang B. A bioactivity-guided study on the anti-diarrheal activity of Polygonum chinense Linn. J Ethnopharmacol. 2013;149:499-505. doi:10.1016/j.jep.2013.07.007.

45. Louise IM, Walker R, Catherine BP, Augustin S. Risks and safety of polyphenol consumption. Am J Clin Nutr. 2005;81:326S-9.

46. Cerda B, Ceron JJ, Tomas-Barberan FA, Espin JC. Repeated oral administration of high doses of the pomegranate ellagitannin punicalagin to rats for 37 days is not toxic. J Agric Food Chem. 2003:51:3493-501.

47. Joshua DL, Mary JK, Shengmin S, Kenneth RR, Jihyeung J, Chung SY. Hepatotoxicity of high oral dose (-)-Epigallocatechin-3-Gallate in mice. Food Chem Toxicol. 2010;48(1):409-16. doi:10.1016/j.fct.2009.10.030.

48. Isomura T, Suzuki S, Origasa H, Hosono A, Suzuki M, Sawada T, Terao S, Muto Y, Koga T. Liver-related safety assessment of green tea extracts in humans: a systematic review of randomized controlled trials. Eur J Clin Nutr. 2016:70:1221-9. 